\title{
Weak and strong convergence of an explicit iteration process for an asymptotically quasi-i-nonexpansive mapping in Banach spaces
}

\author{
Yunus Purtas ${ }^{a}$, Hukmi Kiziltunc $c^{b, *}$ \\ ${ }^{a}$ Banking and Insurance Department, Ahmetli Vocational Higher School, Celal Bayar University, Manisa, Turkey. \\ ${ }^{b}$ Department of Mathematics, Faculty of Science, Ataturk University, Erzurum, Turkey. \\ Dedicated to George A Anastassiou on the occasion of his sixtieth birthday \\ Communicated by Professor D. Turkoglu
}

\begin{abstract}
In this paper, we prove the weak and strong convergence of an explicit iterative process to a common fixed point of an asymptotically quasi- $I$-nonexpansive mapping $T$ and an asymptotically quasi-nonexpansive mapping $I$, defined on a nonempty closed convex subset of a Banach space.
\end{abstract}

Keywords: Asymptotically quasi-I-nonexpansive self-mappings, explicit iterations, common fixed point, uniformly convex Banach space.

2010 MSC: Primary 47H09; Secondary 47H10.

\section{Introduction}

Let $K$ be a nonempty subset of a real normed linear space $X$ and let $T: K \rightarrow K$ be a mapping. Denote by $F(T)$ the set of fixed points of $T$, that is, $F(T)=\{x \in K: T x=x\}$ and we denote by $D(T)$ the domain of a mapping $T$. Throughout this paper, we assume that $X$ is a real Banach space and $F(T) \neq \emptyset$. Now, we recall some well-known concepts and results.

Definition 1.1. A mapping $T: K \rightarrow K$ is said to be

1. nonexpansive, if $\|T x-T y\| \leq\|x-y\|$ for all $x, y \in K$;

\footnotetext{
*Corresponding author

Email addresses: yunus.purtas@cbu.edu.tr (Yunus Purtas), hukmu@atauni.edu.tr (Hukmi Kiziltunc)
} 
2. asymptotically nonexpansive, if there exists a sequence $\left\{\lambda_{n}\right\} \subset[1, \infty)$ with $\lim _{n \rightarrow \infty} \lambda_{n}=1$ such that $\left\|T^{n} x-T^{n} y\right\| \leq \lambda_{n}\|x-y\|$ for all $x, y \in K$ and $n \in N$;

3. quasi-nonexpansive, if $\|T x-p\| \leq\|x-p\|$ for all $x \in K, p \in F(T)$;

4. asymptotically quasi-nonexpansive, if there exists a sequence $\left\{\mu_{n}\right\} \subset[1, \infty)$ with $\lim _{n \rightarrow \infty} \mu_{n}=1$ such that $\left\|T^{n} x-p\right\| \leq \mu_{n}\|x-p\|$ for all $x \in K, p \in F(T)$ and $n \in N$.

The first nonlinear ergodic theorem was proved by Baillon [1] for general nonexpansive mappings in Hilbert space $H$ : if $K$ is a closed and convex subset of $H$ and $T$ has a fixed point, then every $x \in K,\left\{T^{n} x\right\}$ is weakly almost convergent, as $n \rightarrow \infty$, to a fixed point of $T$. It was also shown by Pazy [2] that if $H$ is a real Hilbert space and $\left(\frac{1}{n}\right) \sum_{i=0}^{n-1} T^{i} x$ converges weakly, as $n \rightarrow \infty$, to $y \in K$, then $y \in F(T)$.

In [3], 4] Browder studied the iterative construction for fixed points of nonexpansive mappings on closed and convex subsets of a Hilbert space. The concept of a quasi-nonexpansive mapping was initiated by Tricomi in 1941 for real functions. Kiziltunc et al. [5] studied common fixed points of two nonself nonexpansive mappings in Banach Spaces. Khan [8] presented a two-step iterative process for two asymptotically quasi-nonexpansive mappings. Fukhar-ud-din and Khan [9] studied convergence of iterates with errors of asymptotically quasi-nonexpansive mappings and applications. Diaz and Metcalf [7] and Dotson [10] studied quasi-nonexpansive mappings in Banach spaces. Subsequently, the convergence of Ishikawa iterates of quasi-nonexpansive mappings in Banach spaces was discussed by Ghosh and Debnath [11. The iterative approximation problems for nonexpansive mapping, were studied extensively by Goebel and Kirk [12], Liu [13], Wittmann [14, Reich [15], Gornicki [16], Schu [17], Shioji and Takahashi [18, and Tan and Xu [19] in the settings of Hilbert spaces and uniformly convex Banach spaces.

There are many concepts which generalize a notion of nonexpansive mapping. One of such concepts is $I$-nonexpansivity of a mapping $\mathrm{T}[20$. Let us recall some notions.

Definition 1.2. Let $T: K \rightarrow K, I: K \rightarrow K$ be two mappings of nonempty subset $K$ of a real normed linear space $X$. Then $T$ is said to be

1. I-nonexpansive, if $\|T x-T y\| \leq\|I x-I y\|$ for all $x, y \in K$;

2. asymptotically I-nonexpansive, if there exists a sequence $\left\{\lambda_{n}\right\} \subset[1, \infty)$ with $\lim _{n \rightarrow \infty} \lambda_{n}=1$ such that $\left\|T^{n} x-T^{n} y\right\| \leq \lambda_{n}\left\|I^{n} x-I^{n} y\right\|$ for all $x, y \in K$ and $n \geq 1$

3. quasi I-nonexpansive, if $\|T x-p\| \leq\|I x-p\|$ for all $x \in K, p \in F(T) \cap F(I)$;

4. asymptotically quasi I-nonexpansive, if there exists a sequance $\left\{\mu_{n}\right\} \subset[1, \infty)$ with $\lim _{n \rightarrow \infty} \mu_{n}=1$ such that $\left\|T^{n} x-p\right\| \leq \mu_{n}\left\|I^{n} x-p\right\|$ for all $x \in K, p \in F(T) \cap F(I)$ and $n \geq 1$.

Remark 1.3. If $F(T) \cap F(I) \neq \emptyset$ then an asymptotically I-nonexpansive mapping is asymptotically quasi I-nonexpansive.

Best approximation properties of $I$-nonexpansive mappings were investigated in [20]. In [21] strong convergence of Mann iterations of $I$-nonexpansive mapping has been proved. In [22] the weak and strong convergence of implicit iteration process to a common fixed point of a finite family of $I$-asymptotically nonexpansive mappings were proved. In [23] the weak convergence theorems of three-step iterative scheme for an I-quasi-nonexpansive mappings in a Banach space has been studied. In [24] a weakly convergence theorem for $I$-asymptotically quasi-nonexpansive mapping defined in Hilbert space was proved. Mukhamedov and Saburov [27] studied weak and strong convergence of an implicit iteration process for an asymptotically quasiI-nonexpansive mapping in Banach space. In [28] Mukhamedov and Saburov studied strong convergence of an explicit iteration process for a totally asymptotically $I$-nonexpansive mapping in Banach spaces. This iteration scheme is defined as follows.

Let $K$ be a nonemty closed convex subset of a real Banach space $X$. Consider $T: K \rightarrow K$ an asymptotically quasi $I$-nonexpansive mapping, where $I: K \rightarrow K$ an asymptotically quasi-nonexpansive mapping. Then for two given sequences $\left\{\alpha_{n}\right\},\left\{\beta_{n}\right\}$ in $[0,1]$ we shall consider the following iteration scheme:

$$
\left\{\begin{array}{c}
x_{0} \in K, \\
x_{n+1}=\left(1-\alpha_{n}\right) x_{n}+\alpha_{n} T^{n} y_{n}, n \geq 0, \\
y_{n}=\left(1-\beta_{n}\right) x_{n}+\beta_{n} I^{n} x_{n} .
\end{array}\right.
$$


Inspired and motivated by these facts, we study the convergence of an explicit iterative involving an asymptotically quasi- $I$-nonexpansive mapping in nonempty closed convex subset of uniformly convex Banach spaces.

In this paper, we prove weak and strong convergences of an explicit iterative process (1.1) to a common fixed point of $T$ and $I$.

\section{Preliminaries}

Recall that a Banach space $X$ is said to satisfy Opial condition [25] if, for each sequence $\left\{x_{n}\right\}$ in $X$ such that $\left\{x_{n}\right\}$ converges weakly to $x$ implies that

$$
\lim _{n \rightarrow \infty} \inf \left\|x_{n}-x\right\|<\lim _{n \rightarrow \infty} \inf \left\|x_{n}-y\right\|
$$

for all $y \in X$ with $y \neq x$. It is weel known that (see [26] ) inequality (2.1) is equivalent to

$$
\lim _{n \rightarrow \infty} \sup \left\|x_{n}-x\right\|<\lim _{n \rightarrow \infty} \sup \left\|x_{n}-y\right\| .
$$

Definition 2.1. Let $K$ be a closed subset of a real Banach space $X$ and let $T: K \rightarrow K$ be a mapping.

1. A mapping $T$ is said to be semiclosed (demiclosed) at zero, if for each bounded sequence $\left\{x_{n}\right\}$ in $K$, the conditions $x_{n}$ converges weakly to $x \in K$ and $T x_{n}$ converges strongly to 0 imply $T x=0$.

2. A mapping $T$ is said to be semicompact, if for any bounded sequence $\left\{x_{n}\right\}$ in $K$ such that $\left\|x_{n}-T x_{n}\right\| \rightarrow$ $0, n \rightarrow \infty$, then there exists a subsequence $\left\{x_{n_{k}}\right\} \subset\left\{x_{n}\right\}$ such that $x_{n_{k}} \rightarrow x^{*} \in K$ strongly.

3. $T$ is called a uniformly L-Lipschitzian mapping, if there exists a constant $L>0$ such that $\left\|T^{n} x-T^{n} y\right\| \leq$ $L\|x-y\|$ for all $x, y \in K$ and $n \geq 1$.

Lemma 2.2. [17] Let $X$ be a uniformly convex Banach space and let $b, c$ be two constant with $0<b<c<1$. Suppose that $\left\{t_{n}\right\}$ is a sequence in $[b, c]$ and $\left\{x_{n}\right\},\left\{y_{n}\right\}$ are two sequence in $X$ such that

$$
\lim _{n \rightarrow \infty}\left\|t_{n} x_{n}+\left(1-t_{n}\right) y_{n}\right\|=d, \quad \lim _{n \rightarrow \infty} \sup \left\|x_{n}\right\| \leq d, \quad \lim \sup \left\|y_{n}\right\| \leq d,
$$

holds some $d \geq 0$. Then $\lim _{n \rightarrow \infty}\left\|x_{n}-y_{n}\right\|=0$.

Lemma 2.3. [19] Let $\left\{a_{n}\right\}$ and $\left\{b_{n}\right\}$ be two sequences of nonnegative real numbers with $\sum_{n=1}^{\infty} b_{n}<\infty$. If one of the following conditions is satisfied:

1. $a_{n+1} \leq a_{n}+b_{n}, \quad n \geq 1$,

2. $a_{n+1} \leq\left(1+b_{n}\right) a_{n}, \quad n \geq 1$,

then the limit $\lim _{n \rightarrow \infty} a_{n}$ exists.

\section{Main Results}

In this section, we prove convergence theorems of an explicit iterative scheme (1.1) for an asymptotically quasi- $I$-nonexpansive mapping in Banach spaces. In order to prove our main results, the following lemmas are needed.

Lemma 3.1. Let $X$ be a real Banach space and let $K$ be a nonempty closed convex subset of $X$. Let $T: K \rightarrow K$ be an asymptotically quasi-I-nonexpansive mapping with a sequence $\left\{\lambda_{n}\right\} \subset[1, \infty)$ and $I$ : $K \rightarrow K$ be an asymptotically quasi-nonexpansive mapping with a sequence $\left\{\mu_{n}\right\} \subset[1, \infty)$ such that $\mathcal{F}=$ $F(T) \cap F(I) \neq \emptyset$. Suppose $N=\lim _{n} \lambda_{n} \geq 1, M=\lim _{n} \mu_{n} \geq 1$ and $\left\{\alpha_{n}\right\},\left\{\beta_{n}\right\}$ are two sequences in $[0,1]$ such that $\sum_{n=1}^{\infty}\left(\lambda_{n} \mu_{n}-1\right) \alpha_{n}<\infty$. If $\left\{x_{n}\right\}$ is an explicit iterative sequence defined by (1.1), then for each $p \in \mathcal{F}=F(T) \cap F(I)$ the limit $\lim _{n \rightarrow \infty}\left\|x_{n}-p\right\|$ exists. 
Proof. Since $p \in \mathcal{F}=F(T) \cap F(I)$, for any given $p \in F$, it follows 1.1) that

$$
\begin{aligned}
\left\|x_{n+1}-p\right\| & \leq\left(1-\alpha_{n}\right)\left\|x_{n}-p\right\|+\alpha_{n}\left\|T^{n} y_{n}-p\right\| \\
& \leq\left(1-\alpha_{n}\right)\left\|x_{n}-p\right\|+\alpha_{n} \lambda_{n}\left\|I^{n} y_{n}-p\right\| \\
& \leq\left(1-\alpha_{n}\right)\left\|x_{n}-p\right\|+\alpha_{n} \lambda_{n} \mu_{n}\left\|y_{n}-p\right\| .
\end{aligned}
$$

Again from (1.1) we derive that

$$
\begin{aligned}
\left\|y_{n}-p\right\| & \leq\left(1-\beta_{n}\right)\left\|x_{n}-p\right\|+\beta_{n}\left\|I^{n} x_{n}-p\right\| \\
& \leq\left(1-\beta_{n}\right)\left\|x_{n}-p\right\|+\beta_{n} \mu_{n}\left\|x_{n}-p\right\| \\
& \leq\left(1-\beta_{n}\right) \mu_{n}\left\|x_{n}-p\right\|+\beta_{n} \mu_{n}\left\|x_{n}-p\right\| \\
& \leq \mu_{n}\left\|x_{n}-p\right\|,
\end{aligned}
$$

which means

$$
\left\|y_{n}-p\right\| \leq \mu_{n}\left\|x_{n}-p\right\| \leq \lambda_{n} \mu_{n}\left\|x_{n}-p\right\|
$$

Then from 3.3 we have

$$
\left\|x_{n+1}-p\right\| \leq\left[1+\alpha_{n}\left(\lambda_{n}^{2} \mu_{n}^{2}-1\right)\right]\left\|x_{n}-p\right\| .
$$

By putting $b_{n}=\alpha_{n}\left(\lambda_{n}^{2} \mu_{n}^{2}-1\right)$ the last inequality can be rewritten as follows:

$$
\left\|x_{n+1}-p\right\| \leq\left(1+b_{n}\right)\left\|x_{n}-p\right\| .
$$

By hypothesis we find

$$
\begin{aligned}
\sum_{n=1}^{\infty} b_{n} & =\sum_{n=1}^{\infty} \alpha_{n}\left(\lambda_{n}^{2} \mu_{n}^{2}-1\right) \\
& =\sum_{n=1}^{\infty}\left(\lambda_{n} \mu_{n}+1\right)\left(\lambda_{n} \mu_{n}-1\right) \alpha_{n} \\
& \leq(N M+1) \sum_{n=1}^{\infty}\left(\lambda_{n} \mu_{n}-1\right) \alpha_{n}<\infty .
\end{aligned}
$$

Defining $a_{n}=\left\|x_{n}-p\right\|$ in 3.5$)$ we have

$$
a_{n+1} \leq\left(1+b_{n}\right) a_{n},
$$

and Lemma 2.3 implies the existence of the $\operatorname{limit}_{n \rightarrow \infty} a_{n}$. The means the limit

$$
\lim _{n \rightarrow \infty}\left\|x_{n}-p\right\|=d
$$

exists, where $d \geq 0$ constant. This completes the proof.

Theorem 3.2. Let $X$ be a real Banach space and let $K$ be a nonempty closed convex subset of $X$. Let $T: K \rightarrow K$ be a unifornly $L_{1}$-Lipschitzian asymptotically quasi-I-nonexpansive mapping with a sequence $\left\{\lambda_{n}\right\} \subset[1, \infty)$ and $I: K \rightarrow K$ be a unifornly $L_{2}$-Lipschitzian asymptotically quasi-nonexpansive mapping with a sequence $\left\{\mu_{n}\right\} \subset[1, \infty)$ such that $\mathcal{F}=F(T) \cap F(I) \neq \emptyset$. Suppose $N=\lim _{n} \lambda_{n} \geq 1, M=\lim _{n} \mu_{n} \geq 1$ and $\left\{\alpha_{n}\right\},\left\{\beta_{n}\right\}$ are two sequences in $[0,1]$ such that $\sum_{n=1}^{\infty}\left(\lambda_{n} \mu_{n}-1\right) \alpha_{n}<\infty$. Then an explicit iterative sequence $\left\{x_{n}\right\}$ defined by (1.1) converges strongly to a common fixed point in $\mathcal{F}=F(T) \cap F(I)$ if and only if

$$
\lim _{n \rightarrow \infty} \inf d\left(x_{n}, F\right)=0
$$


Proof. The necessity of condition (3.7) is obvious. Let us prove the sufficiency part of theorem. Since $T, I: K \rightarrow K$ are uniformly $L$-Lipschitzian mappings, so $T$ and $I$ are continuous mappings. Therefore the sets $F(T)$ and $F(I)$ are closed. Hence $\mathcal{F}=F(T) \cap F(I)$ is a nonempty closed set.

For any given $p \in F$, we have

$$
\left\|x_{n+1}-p\right\| \leq\left(1+b_{n}\right)\left\|x_{n}-p\right\|,
$$

as before where $b_{n}=\alpha_{n}\left(\lambda_{n}^{2} \mu_{n}^{2}-1\right)$ with $\sum_{n=1}^{\infty} b_{n}<\infty$. Hence, we have

$$
d\left(x_{n+1}, F\right) \leq\left(1+b_{n}\right) d\left(x_{n}, F\right) .
$$

From (3.9) due to Lemma 2.3 we obtain the existence of the $\operatorname{limit}_{n \rightarrow \infty} d\left(x_{n} F\right)$. By condition (3.7), we get

$$
\lim _{n \rightarrow \infty} d\left(x_{n}, F\right)=\lim _{n \rightarrow \infty} \inf d\left(x_{n}, F\right)=0 .
$$

Let us prove that the sequence $\left\{x_{n}\right\}$ converges to a common fixed point of $T$ and $I$. In fact, due to $1+t \leq \exp (t)$ for all $t>0$, and from (3.8), we obtain

$$
\left\|x_{n+1}-p\right\| \leq \exp \left(b_{n}\right)\left\|x_{n}-p\right\| .
$$

Hence, for any positive integers $m, n$ from (3.11) with $\sum_{n=1}^{\infty} b_{n}<\infty$ we find

$$
\begin{aligned}
\left\|x_{n+m}-p\right\| & \leq \exp \left(b_{n+m-1}\right)\left\|x_{n+m-1}-p\right\| \\
& \leq \exp \left(\sum_{i=n}^{n+m-1} b_{i}\right)\left\|x_{n}-p\right\| \\
& \leq \exp \left(\sum_{i=1}^{\infty} b_{i}\right)\left\|x_{n}-p\right\|,
\end{aligned}
$$

which means that

$$
\left\|x_{n+m}-p\right\| \leq W\left\|x_{n}-p\right\|
$$

for all $p \in F$, where $W=\exp \left(\sum_{i=1}^{\infty} b_{i}\right)<\infty$.

Since $\lim _{n \rightarrow \infty} d\left(x_{n} F\right)=0$, then for any given $\varepsilon>0$, there exists a positive integer number $n_{0}$ such that

$$
d\left(x_{n_{0}}, F\right)<\frac{\varepsilon}{W} .
$$

Therefore there exists $p_{1} \in F$ such that

$$
\left\|x_{n_{0}}-p_{1}\right\|<\frac{\varepsilon}{W}
$$

Consequently, for all $n \geq n_{0}$ from (3.14) we derive

$$
\begin{aligned}
\left\|x_{n}-p_{1}\right\| & \leq W\left\|x_{n_{0}}-p_{1}\right\| \\
& <W \cdot \frac{\varepsilon}{W} \\
& =\varepsilon,
\end{aligned}
$$

which means that the strong convergence limit of the sequence $\left\{x_{n}\right\}$ is a common fixed point $p_{1}$ of $T$ and $I$. This completes the proof.

Lemma 3.3. Let $X$ be a real uniformly Banach space and let $K$ be a nonempty closed convex subset of $X$. Let $T: K \rightarrow K$ be a unifornly $L_{1}$-Lipschitzian asymptotically quasi-I-nonexpansive mapping with a sequence $\left\{\lambda_{n}\right\} \subset[1, \infty)$ and $I: K \rightarrow K$ be a unifornly $L_{2}$-Lipschitzian asymptotically quasinonexpansive mapping with a sequence $\left\{\mu_{n}\right\} \subset[1, \infty)$ such that $\mathcal{F}=F(T) \cap F(I) \neq \emptyset$. Suppose $N=$ $\lim _{n} \lambda_{n} \geq 1, M=\lim _{n} \mu_{n} \geq 1$ and $\left\{\alpha_{n}\right\},\left\{\beta_{n}\right\}$ are sequences in $[t, 1-t]$ for some $t \in(0,1)$ such that $\sum_{n=1}^{\infty}\left(\lambda_{n} \mu_{n}-1\right) \alpha_{n}<\infty$. Then an explicit iterative sequence $\left\{x_{n}\right\}$ defined by (1.1) satisfies the following:

$$
\lim _{n \rightarrow \infty}\left\|x_{n}-T x_{n}\right\|=0, \quad \lim _{n \rightarrow \infty}\left\|x_{n}-I x_{n}\right\|=0 .
$$


Proof. First, we will prove that

$$
\lim _{n \rightarrow \infty}\left\|x_{n}-T^{n} x_{n}\right\|=0, \quad \lim _{n \rightarrow \infty}\left\|x_{n}-I^{n} x_{n}\right\|=0 .
$$

According to Lemma 3.1 for any $p \in \mathcal{F}=F(T) \cap F(I)$ we have $\lim _{n \rightarrow \infty}\left\|x_{n}-p\right\|=d$. It follows from 1.1 that

$$
\left\|x_{n+1}-p\right\|=\left\|\left(1-\alpha_{n}\right)\left(x_{n}-p\right)+\alpha_{n}\left(T^{n} y_{n}-p\right)\right\| \rightarrow d, \quad n \rightarrow \infty .
$$

By means of asymptotically quasi- $I$-nonexpansivity of $T$ and asymptotically quasi-nonexpansivity of $I$ from (3.3) we get

$$
\lim _{n \rightarrow \infty} \sup \left\|T^{n} y_{n}-p\right\| \leq \lim _{n \rightarrow \infty} \sup \lambda_{n} \mu_{n}\left\|y_{n}-p\right\| \leq \lim _{n \rightarrow \infty} \sup \lambda_{n}^{2} \mu_{n}^{2}\left\|x_{n}-p\right\|=d .
$$

Now using

$$
\lim _{n \rightarrow \infty} \sup \left\|x_{n}-p\right\|=d,
$$

with (3.21) and applying Lemma 2.2 to 3.20 we obtain

$$
\lim _{n \rightarrow \infty}\left\|x_{n}-T^{n} y_{n}\right\|=0 .
$$

Now from (1.1) and 3.22 we infer that

$$
\lim _{n \rightarrow \infty}\left\|x_{n+1}-x_{n}\right\|=\lim _{n \rightarrow \infty}\left\|\alpha_{n}\left(T^{n} y_{n}-x_{n}\right)\right\|=0 .
$$

From 3.23$)$ and 3.24 we get

$$
\lim _{n \rightarrow \infty}\left\|x_{n+1}-T^{n} y_{n}\right\| \leq \lim _{n \rightarrow \infty}\left\|x_{n+1}-x_{n}\right\|+\lim _{n \rightarrow \infty}\left\|x_{n}-T^{n} y_{n}\right\|=0 .
$$

On the other hand, we have

$$
\begin{aligned}
\left\|x_{n}-p\right\| & \leq\left\|x_{n}-T^{n} y_{n}\right\|+\left\|T^{n} y_{n}-p\right\| \\
& \leq\left\|x_{n}-T^{n} y_{n}\right\|+\lambda_{n} \mu_{n}\left\|y_{n}-p\right\|,
\end{aligned}
$$

which implies

$$
\left\|x_{n}-p\right\|-\left\|x_{n}-T^{n} y_{n}\right\| \leq \lambda_{n} \mu_{n}\left\|y_{n}-p\right\| .
$$

The last inequality with $(3.3)$ yields that

$$
\left\|x_{n}-p\right\|-\left\|x_{n}-T^{n} y_{n}\right\| \leq \lambda_{n} \mu_{n}\left\|y_{n}-p\right\| \leq \lambda_{n}^{2} \mu_{n}^{2}\left\|x_{n}-p\right\| .
$$

Then 3.22 and $(3.23)$ with the Squeeze Theorem imply that

$$
\lim _{n \rightarrow \infty}\left\|y_{n}-p\right\|=d
$$

Again from (1.1) we can see that

$$
\left\|y_{n}-p\right\|=\left\|\left(1-\beta_{n}\right)\left(x_{n}-p\right)+\beta_{n}\left(I^{n} x_{n}-p\right)\right\| \rightarrow \infty, \quad n \rightarrow \infty .
$$

From (3.7) one finds

$$
\lim _{n \rightarrow \infty} \sup \left\|I^{n} x_{n}-p\right\| \leq \lim _{n \rightarrow \infty} \sup \mu_{n}\left\|x_{n}-p\right\|=d .
$$

Now applying Lemma 2.2 to 3.29 we obtain

$$
\lim _{n \rightarrow \infty}\left\|x_{n}-I^{n} x_{n}\right\|=0 .
$$


From (3.24) and (3.32) we have

$$
\lim _{n \rightarrow \infty}\left\|x_{n+1}-I^{n} x_{n}\right\| \leq \lim _{n \rightarrow \infty}\left\|x_{n+1}-x_{n}\right\|+\lim _{n \rightarrow \infty}\left\|x_{n}-I^{n} x_{n}\right\|=0 .
$$

It follows from 1.1 that

$$
\left\|y_{n}-x_{n}\right\|=\beta_{n}\left\|x_{n}-I^{n} x_{n}\right\| .
$$

Hence, from (3.32) and (3.34) we obtain

$$
\lim _{n \rightarrow \infty}\left\|y_{n}-x_{n}\right\|=0
$$

Consider

$$
\left\|x_{n}-T^{n} x_{n}\right\| \leq\left\|x_{n}-T^{n} y_{n}\right\|+L_{1}\left\|y_{n}-x_{n}\right\| .
$$

Then from $(3.23)$ and 3.35 we obtain

$$
\lim _{n \rightarrow \infty}\left\|x_{n}-T^{n} x_{n}\right\|=0 .
$$

From (3.24) and 3.35 we have

$$
\lim _{n \rightarrow \infty}\left\|x_{n+1}-y_{n}\right\| \leq \lim _{n \rightarrow \infty}\left\|x_{n+1}-x_{n}\right\|+\lim _{n \rightarrow \infty}\left\|y_{n}-x_{n}\right\|=0 .
$$

Finally, from

$$
\left\|x_{n}-T x_{n}\right\| \leq\left\|x_{n}-T^{n} x_{n}\right\|+L_{1}\left\|x_{n}-y_{n-1}\right\|+L_{1}\left\|T^{n-1} y_{n-1}-x_{n}\right\|,
$$

which with 3.25), 3.37) and (3.38) we get

$$
\lim _{n \rightarrow \infty}\left\|x_{n}-T x_{n}\right\|=0 .
$$

Similarly, one has

$$
\left\|x_{n}-I x_{n}\right\| \leq\left\|x_{n}-I^{n} x_{n}\right\|+L_{2}\left\|x_{n}-x_{n-1}\right\|+L_{2}\left\|I^{n-1} x_{n-1}-x_{n}\right\|,
$$

which with $3.24,(3.32)$ and 3.33 implies

$$
\lim _{n \rightarrow \infty}\left\|x_{n}-I x_{n}\right\|=0 .
$$

This completes the proof.

Theorem 3.4. Let $X$ be a real uniformly convex Banach space satisfying Opial condition and let $K$ be a nonempty closed convex subset of $X$. Let $E: X \rightarrow X$ be an identity mapping, let $T: K \rightarrow K$ be a unifornly $L_{1}$-Lipschitzian asymptotically quasi-I-nonexpansive mapping with a sequence $\left\{\lambda_{n}\right\} \subset[1, \infty)$ , and $I: K \rightarrow K$ be a unifornly $L_{2}$-Lipschitzian asymptotically quasi-nonexpansive mapping with a sequence $\left\{\mu_{n}\right\} \subset[1, \infty)$ such that $\mathcal{F}=F(T) \cap F(I) \neq \emptyset$. Suppose $N=\lim _{n} \lambda_{n} \geq 1, M=\lim _{n} \mu_{n} \geq 1$ and $\left\{\alpha_{n}\right\},\left\{\beta_{n}\right\}$ are sequences in $[t, 1-t]$ for some $t \in(0,1)$ such that $\sum_{n=1}^{\infty}\left(\lambda_{n} \mu_{n}-1\right) \alpha_{n}<\infty$. If the mappings $E-T$ and $E-I$ are semiclosed at zero, then an explicit iterative sequence $\left\{x_{n}\right\}$ defined by (1.1) converges weakly to a common fixed point of $T$ and $I$.

Proof. Let $p \in F$, then according to Lemma 3.1 the sequence $\left\{\left\|x_{n}-p\right\|\right\}$ converges. This provides that $\left\{x_{n}\right\}$ is a bounded sequence. Since $X$ is uniformly convex, then every bounded subset of $X$ is weakly compact. Since $\left\{x_{n}\right\}$ is a bounded sequence in $K$, then there exists a subsequence $\left\{x_{n_{k}}\right\} \subset\left\{x_{n}\right\}$ such that $\left\{x_{n_{k}}\right\}$ converges weakly to $q \in K$. Hence, from (3.40) and (3.42) it follows that

$$
\lim _{n_{k} \rightarrow \infty}\left\|x_{n_{k}}-T x_{n_{k}}\right\|=0, \quad \lim _{n_{k} \rightarrow \infty}\left\|x_{n_{k}}-I x_{n_{k}}\right\|=0 .
$$


Since the mappings $E-T$ and $E-I$ are semiclosed at zero, therefore, we find $T q=q$ and $I q=q$, which means $q \in \mathcal{F}=F(T) \cap F(I)$.

Finally, let us prove that $\left\{x_{n}\right\}$ converges weakly to $q$. In fact, suppose the contrary, that is, there exists some subsequence $\left\{x_{n_{j}}\right\} \subset\left\{x_{n}\right\}$ such that $\left\{x_{n_{j}}\right\}$ converges weakly to $q_{1} \in K$ and $q_{1} \neq q$. Then by the same method as given above, we can also prove that $q_{1} \in \mathcal{F}=F(T) \cap F(I)$.

Taking $p=q$ and $p=q_{1}$ and using the same argument given in the proof of (3.7), we can prove that the limits $\lim _{n \rightarrow \infty}\left\|x_{n}-q\right\|$ and $\lim _{n \rightarrow \infty}\left\|x_{n}-q_{1}\right\|$ exist, and we have

$$
\lim _{n \rightarrow \infty}\left\|x_{n}-q\right\|=d, \quad \lim _{n \rightarrow \infty}\left\|x_{n}-q_{1}\right\|=d_{1},
$$

where $d$ and $d_{1}$ are two nonnegative numbers. By virtue of the Opial condition of $X$, we obtain

$$
\begin{aligned}
d & =\lim _{n_{k} \rightarrow \infty} \sup \left\|x_{n_{j}}-q\right\|<\lim _{n_{k} \rightarrow \infty} \sup \left\|x_{n_{k}}-q_{1}\right\|=d_{1} \\
& =\lim _{n_{j} \rightarrow \infty} \sup \left\|x_{n_{j}}-q_{1}\right\|<\lim _{n_{j} \rightarrow \infty} \sup \left\|x_{n_{j}}-q\right\| .
\end{aligned}
$$

This is a contradiction. Hence $q_{1}=q$. This implies that $\left\{x_{n}\right\}$ converges weakly to $q$. This completes the proof.

Theorem 3.5. Let $X$ be a real uniformly convex Banach space and let $K$ be a nonempty closed convex subset of $X$. Let $T: K \rightarrow K$ be a unifornly $L_{1}$-Lipschitzian asymptotically quasi-I-nonexpansive mapping with a sequence $\left\{\lambda_{n}\right\} \subset[1, \infty)$, and $I: K \rightarrow K$ be a unifornly $L_{2}$-Lipschitzian asymptotically quasinonexpansive mapping with a sequence $\left\{\mu_{n}\right\} \subset[1, \infty)$ such that $\mathcal{F}=F(T) \cap F(I) \neq \emptyset$. Suppose $N=$ $\lim _{n} \lambda_{n} \geq 1, M=\lim _{n} \mu_{n} \geq 1$ and $\left\{\alpha_{n}\right\},\left\{\beta_{n}\right\}$ are sequences in $[t, 1-t]$ for some $t \in(0,1)$ such that $\sum_{n=1}^{\infty}\left(\lambda_{n} \mu_{n}-1\right) \alpha_{n}<\infty$. If at least one mapping of the mappings $T$ and $I$ is semicompact, then an explicit iterative sequence $\left\{x_{n}\right\}$ defined by (1.1) converges strongly to a common fixed point of $T$ and $I$.

Proof. Without any loss of generality, we may assume taht $T$ is semicompact. This with 3.40 means that there exists a subsequence $\left\{x_{n_{k}}\right\} \subset\left\{x_{n}\right\}$ such that $x_{n_{k}} \rightarrow x^{*}$ strongly and $x^{*} \in K$. Since $T, I$ are continuous, then from 3.40$)$ and $(3.42)$ we find

$$
\left\|x^{*}-T x^{*}\right\|=\lim _{n_{k} \rightarrow \infty}\left\|x_{n_{k}}-T x_{n_{k}}\right\|=0, \quad\left\|x^{*}-I x^{*}\right\|=\lim _{n_{k} \rightarrow \infty}\left\|x_{n_{k}}-I x_{n_{k}}\right\|=0 .
$$

This shows taht $x^{*} \in \mathcal{F}=F(T) \cap F(I)$. According to Lemma 3.1 the limit $\lim _{n \rightarrow \infty}\left\|x_{n}-x^{*}\right\|$ exists. Then

$$
\lim _{n \rightarrow \infty}\left\|x_{n}-x^{*}\right\|=\lim _{n_{k} \rightarrow \infty}\left\|x_{n_{k}}-x^{*}\right\|=0
$$

which means taht $\left\{x_{n}\right\}$ converges to $x^{*} \in F$. This completes the proof.

\section{References}

[1] J. B. Baillon, Un theoreme de type ergodique pour les contractions non lineaires dans un espace de Hilbert, Comptes Rendus de l'Academie des Sciences de Paris, Serie A 280 no. 22 (1975), 1511-1514. 1

[2] A. Pazy, On the asymptotic behavior of iterates of nonexpasive mappings in Hilbert space, Israel Journal of Mathematics, 26 (1977), 197-204. 1

[3] F. E. Browder, Nonexpansive nonlinear operators in a Banach space, Proceedings of the National Academy of Sciences of the United States of America, vol. 54 (1965), 1041-1044. 1

[4] F. E. Browder, Convergence of apporximants to fixed points of nonexpansive non-linear mappings in Banach spaces, Archive for Rational Mechanics and Analysis, vol. 24 (1967), 82-90. 1

[5] H. Kiziltunc, M. Ozdemir and S. Akbulut, On common fixed points of two nonself nonexpansive mappings in Banach Spaces, Chiang Mai J. Sci., 34 (2007), 281-288. 1

[6] C. Chidume, Geometric Properties of Banach Spaces and Nonlinear Iterations, vol. 1965 of Lecture Notes in Mathematics, Springer, London, 2009.

[7] J. B. Diaz and F. T. Metcalf, On the structure of the set of subsequential limit points of seccessive approximations, Bulletin of the American Mathematical Society, vol. 73 (1967), 516-519. 1 
[8] S. H. Khan, A two-step iterative process for two asymptotically quasi-nonexpansive mappings, World Academy of Science, Engineering and Technology, 75 (2011), http://www.waset.org/journals/waset/ 1

[9] H. Fukhar-ud-din, S. H. Khan, Convergence of iterates with errors of asymptotically quasi-nonexpansive mappings and applications, J.Math.Anal.Appl., 328 (2007) 821-829. 1

[10] J. W. G. Dotson, On the Mann iterative process, Transactions of the American Mathematical Society, 149 , no. 1 (1970), 65-73. 1

[11] M. K. Ghosh and L. Debnath, Convergence of Ishikawa iterates of quasi-nonexpansive mappings, Journal of Mathematical Analysis and Applications, 2007, no. 1 (1997) 96-103. 1

[12] K. Goebel and W. A. Kirk, A fixed point theorem for asymptotically nonexpansive mappings, Proceeding of American Mathematical Society, vol. 35 (1972), 171-174. 1

[13] Q. Liu, Iterative sequences for asymptotically quasi-nonexpansive mappings, Journal of Mathematical Analysis and Applications, vol. 259, no. 1 (2001), 1-7. 1

[14] R. Wittmann, Aproximation of fixed points of nonexpansive mappings, Archiv der Mathematik, vol. 58, no. 5 (1992), 486-491. 1

[15] S. Reich, Strong convergence theorems for resolvents of accretive operators in Banach spaces, Journal of Mathematical Analysis and Applications, vol. 75, no. 1 (1980), 287-292. 1

[16] J. Gornicki, Weak convergence theorems for asymptotically nonexpansive mappings in uniformly convex Banach spaces, Commentations Mathematicae Universitatis Carolinae, vol. 30, no. 2 (1989), 249-252. 1

[17] J. Schu, Weak and strong convergence to fixed points of asymptotically nonexpansive mappings, Bulletin of the Australian Mathematical Society, 43 (1991), 153-159. 1, 2.2

[18] N. Shioji and W. Takahashi, Strong convergence theorems for asymptotically nonexpansive semigroups in Hilbert spaces, Nonlinear Analysis: Theory, Methods \& Applications, vol. 178 (1998), 87-99. 1

[19] K. K. Tan and H. K. Xu, Approximating fixed points of nonexpansive mappings by the Ishikawa iteration process, Journal of Mathematical Analysis and Applications, vol. 178 (1993), 301-308. 1.2 .3

[20] N. Shahzad, Generalized I-nonexpansive maps and best approximations in Banach spaces, Demonstratio Mathematica, vol. 37 (2004), 597-600. 1,1

[21] B. H. Rohades and S. Temir, Convergence theorems for I-nonexpansive mapping, International Journal of Mathematics and Mathematical Sciences, vol. 2006 (2006), Article ID 63435, 4 pages. 1

[22] S. Temir, On the convergence theorems of implicit iteration process for a finite family of I-asymptotically nonexpansive mappings, Journal of Computational and Applied Mathematics, vol. 225, no. 2 (2009), 398-405. 1

[23] P. Kumman, W. Kumethong and N. Jewwaiworn, Weak convergence theorems of three-step Noor iterative scheme for I-quasi-nonexpansive mappings in Banach spaces, Applied Mathematical Sciences, vol. 2 (2008), 2915-2920. 1

[24] S.Temir and O. Gul, Convergence theorem for I-asymptotically quasi-nonexpansive mapping in Hilbert space, Journal of Mathematical Analysis and Applications, vol. 329 (2007), 759-765. 1

[25] Z. Opial, Weak convergence of the sequence of successive approximations for nonexpansive mappings, Bulletin of American Mathematical Society, vol. 73 (1967), 591-597. 2

[26] E. Lami Dozo, Multivalued nonexpansive mappings and Opial's condition, Proceedings of the American Mathematical Society, vol. 38 (1973), 286-292. 2

[27] F. Mukhamedov and M. Saburov, Weak and and Strong Convergence of an Implicit Iteration Process for an Asymptotically Quasi-I-Nonexpansive Mapping in Banach Space, Fixed Point Theory and Applications, (2009), 1-13. [1]

[28] F. Mukhamedov and M. Saburov, Strong Convergence of an Explicit Iteration Process for a Totally Asymptotically I-Nonexpansive Mapping in Banach Spaces, Applied Mathematics Letters, 124 (2010), 1473-1478. 1 